\title{
Effect of backwash and powder activated carbon (PAC) addition on performance of side stream membrane filtration system (SSMFS) on treatment of biological treatment effluent
}

\author{
Paul Smith, Saravanamuthu Vigneswaran* \\ Faculty of Engineering, University of Technology, Sydney, PO Box 123, Broadway, NSW, 2007, Australia \\ Tel.+61-1-954 2641; Fax.+61-2-9514 2633; email: s.vigneswaran@uts.edu.au
}

Received 23 April 2009; Accepted 31 August 2009

\begin{abstract}
A B S T R ACT
In this study, a pilot scale Side Stream Membrane Filtration System (SSMFS) was used to demonstrate the need for optimization of backwash conditions and the addition of PAC. Through an investigation of the amount of fouling each cycle that can be restored through backwashing over a short-term, a good operating point for long-term operation was developed. Periodic removal of $1.5 \%$ of the PAC slurry mixture $(7.5 \mathrm{~L}$ out of $500 \mathrm{~L})$ and PAC replacement $(15 \mathrm{~g} / \mathrm{d})$ was found to have a positive impact on the reduction of membrane fouling.
\end{abstract}

Keywords: Membrane; Adsorption; Organic removal; Sewage effluent; Pilot scale study

\section{Introduction}

Combining activated carbon adsorption with microfiltration $(\mathrm{MF})$ is another promising option not only to improve DOC removal efficiency but also reduce organic clogging on the membrane. In the hybrid system, the small molecular species not usually rejected by the membrane alone are adsorbed onto the activated carbon which subsequently can be separated easily by the MF process. As a result, organic compounds are retained from the treated water. There are two types of activated carbon available namely powdered activated carbon (PAC) and granular activated carbon (GAC). Between the two, PAC is preferable due to its large surface area per unit volume and its affinity for a wide range of dissolved organics [1]. PAC adsorption was found to remove $60 \%-75 \%$ of dissolved organic carbon (DOC) from biologically treated wastewater effluent [2].

In the combined system, PAC can be dosed continuously to the membrane reactor or dosed at the beginning of the membrane filtration cycle. Previous studies showed that PAC pre-adsorption contributed

*Corresponding author. to higher DOC and disinfection by-products (DBPs) removal, flux enhancement and fouling reduction; thus prolonging the continuous filtration time $[1,3]$. One of the hybrid system known as submerged membrane adsorption hybrid system (SMAHS) integrate the entire treatment activity including adsorption/biodegradation, liquid-solid separation and sludge accumulation into one single unit, which can offset the disadvantage of the large equipment size and space requirement [1].

In addition, SMAHS has several advantages. The system can be operated consistently for a long period with a very low energy $\left(0.2 \mathrm{kWh} / \mathrm{m}^{3}\right)$ and without any major sludge problems. Using a dose of $10 \mathrm{~g} / \mathrm{L}$ of PAC added at the beginning of the experiment, Guo et al. [1] obtained approximately $84 \%$ of TOC removal for a 15 -day operation. A long term study conducted showed that $10 \mathrm{~g} / \mathrm{L}$ of one off addition of PAC at the beginning of the operation and replacement of $1 \%$ of PAC on a daily basis led to a consistent TOC removal of more than $90 \%$. The PAC dose was found to be less than $20 \mathrm{mg} / \mathrm{L}$ when one considers an operation period of 50 days.

In Chatel-Gerard, France, a new plant was needed to replace the existing direct filtration plant to treat the groundwater. Since the groundwater was in contact with

Presented at CESE-2009, Challenges in Environmental Science \& Engineering, 14-17 July, 2009, Townsville, Queensland, Australia. doi: 10.5004/dwt.2009.8Śrr 
surface water it suffered occasional (and significant) increases in turbidity, color, TOC, coliforms, and atrazine. For this purpose, a PAC mixing/adsorption tank followed by ultrafiltration (UF) system was chosen due to its suitability and cost. The plant capacity is $600 \mathrm{~m}^{3} / \mathrm{d}$, which, with an average flux of $100 \mathrm{~L} / \mathrm{m}^{2} . \mathrm{h}$, translates to six Aquasource modules each with a $70-\mathrm{m}^{2}$ surface area. The PAC dose varies between 10 and $15 \mathrm{mg} / \mathrm{L}$, backwashing is once per hour, and chemical cleaning is once per year. Plant data show that the average atrazine is kept below the European standard of $0.1 \mu \mathrm{g} / \mathrm{L}$, with excellent removal of turbidity, coliforms, and odors. Production at Chatel-Gerard began in 1993.

In fact, PAC can provide better physical removal of organic pollutants; yet, the addition of high PAC concentration may lead to the accumulation of carbon on the membrane surface, resulting in membrane fouling. The removal efficiency and membrane fouling depends on several parameters including the pre-adsorption, PAC dose, aeration rate, filtration flux and backwash duration [1].

The previous results also showed that the pretreatment of PAC adsorption helped in the reduction of flux decline in cross-flow ultrafiltration (CFUF) [4]. The reduction in the normalized permeate flux $\left(\mathrm{J} / \mathrm{J}_{0}\right)$ for CFUF after a pretreatment of PAC adsorption (with $1 \mathrm{~g} / \mathrm{L}$ ) was from 1 to 0.71 after 6 hours of operation (i.e. $29 \%$ decline). The decline with no pretreatment was 0.66 (i.e. 34\% decline). Adsorption using larger PAC dosages $(0.5 \mathrm{~g} / \mathrm{L})$ removed the majority of the relatively smaller molecular weight organic compounds (200 to $600 \mathrm{Da}$ ). However, the majority of the relatively larger molecular weight of organic matter could not be removed by adsorption alone. The PAC used had a pore radius from 1 to $5 \mathrm{~nm}$ with mean radius of $1.8 \mathrm{~nm}$. The observed removal of a portion of a large molecular weight of organic matter organics by PAC may have been due to adsorption onto the larger pores, or onto the outer surface of PAC. The molecular weight distribution of organic matter results are consistent with the trend in the flux decline. Organic clogging on the membrane can be minimised through PAC usage in the submerged membrane reactor to adsorb dissolved organic matter and reduce direct organic loading on the membrane.

However, even with PAC addition, membrane flouling cannot be totally alleviated. Backwashing during a membrane filtration process has been found to successfully remove most of the reversible component of the foulant layer leading to reduced transmembrane pressure increases and permeate flux decline. Backwashing also enables the system to operate for a longer time before it is stopped for intensive physical and/or chemical cleaning. The duration and the frequency of the backwash are the vital parameters for successful long-term operation of the system.
A backwash of too short duration results in the failure of the complete removal of the reversible component of the foulant layer. On the other hand, a backwash of too long duration effectively removes the majority or even the entire reversible component of the foulant layer. However, the additional permeate used unnecessarily reduces the productivity of the system in terms of permeate production. This also increases the energy requirement [4].

In this study, a pilot scale Side Stream Membrane Filtration System (SSMFS) was used to demonstrate the need for optimization of backwash conditions and the addition of PAC.

\section{Experimental methodology}

Figure 1 presents details of the Side Stream Membrane Filtration System (SSMFS) used in treating the biologically treated sewage effluent in the Castle Hill sewage treatment plant. The membrane details are given in Table 1.

In an earlier study, a new control system developed with the concept of backwash initiation based on a predetermined transmembrane pressure increase each cycle was found to have improved the system productivity and reduced membrane fouling [5].

The improved results found in the earlier study relied upon allowing the transmembrane pressure each cycle to increase to an amount where a backwash of an adequate duration could restore the majority of the membrane permeability. In the development of this level of increase of the transmembrane pressure each cycle, varied backwash frequencies and durations were used; however this process was rather tedious and optimal frequencies and durations vary from one operating condition of the membrane system to another.

In this study, an incremental predetermined transmembrane pressure increase each cycle was set and a backwash of adequate duration was utilised. This process rapidly identified the amount of transmembrane pressure increase each cycle that could be effectively

Table 1

Characteristics of the hollow fibre membrane used.

\begin{tabular}{ll}
\hline Properties & Hollow fibre membrane \\
\hline $\begin{array}{l}\text { Total surface area }\left(\mathrm{m}^{2}\right), \\
(3500 \text { fibres with } 75 \mathrm{~cm} \text { length) }\end{array}$ & 6 \\
Pore size $(\mu \mathrm{m})$ & 0.01 \\
Material & Polysulphone \\
Inner diameter $(\mathrm{mm})$ & 0.36 \\
Outer diameter $(\mathrm{mm})$ & 0.72 \\
Manufacturer & Polymem, France \\
\hline
\end{tabular}




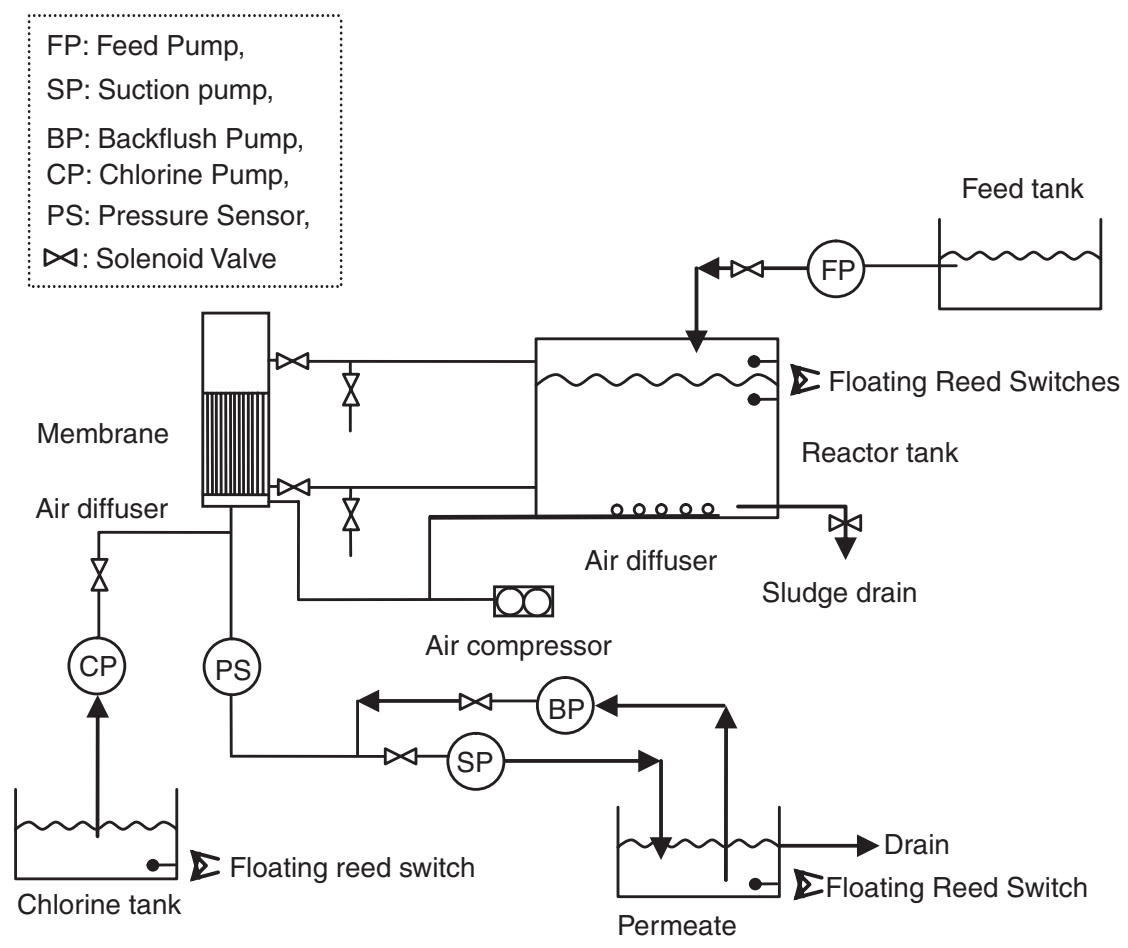

Fig. 1. Schematic of the experimental set-up of the side stream submerged. Membrane filtration system.

removed through backwashing, allowing the experiments to operate for extended durations.

The long-term experiments were conducted using the operating conditions found in the short-term experiments. One experiment involved $2 \mathrm{~g} / \mathrm{L}$ of PAC being dosed into the system (at the start of the experiment) and not replaced throughout the duration of the experiment. The second experiment involved $2 \mathrm{~g} / \mathrm{L}$ of PAC being dosed into the system at the start of the experiment and $1.5 \%$ of the PAC slurry being extracted from the system each day and $1.5 \%$ of the initial PAC dose being dosed into the system.

Backwash was provided for a duration of 2 minutes at a backwash flux of $40 \mathrm{~L} / \mathrm{m}^{2} . h$. The backwash was initiated when the transmembrane pressure increased to $1.5 \mathrm{kPa}$.

\section{Results and discussion}

\subsection{Short-term experiments}

Initially, a series of short-term (50 hour) experiments were conducted at varied allowable amounts of transmembrane pressure increases each cycle (without the addition of PAC). The transmembrane pressure increases (for each cycle) that were used were 1.5, 3 and $4.5 \mathrm{kPa}$.

Figure 2 shows the results of the increase of the transmembrane pressure through the duration of each experiment for varied amounts of allowable transmembrane pressure increases each cycle.

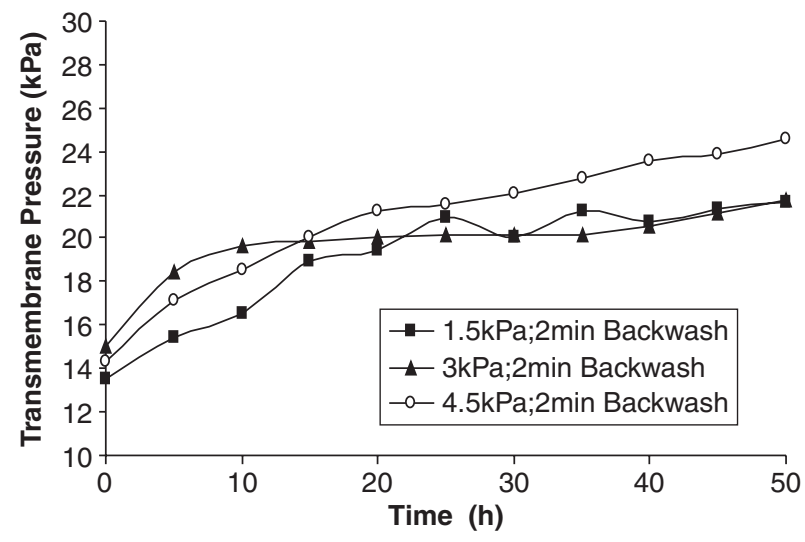

Fig. 2. Transmembrane pressure versus time for variable allowable transmembrane pressure increases each filtration cycle (membrane area $=6 \mathrm{~m}^{2}$, initial permeate flux $=20 \mathrm{~L} / \mathrm{m}^{2} \cdot \mathrm{h}$, backwash flux $=40 \mathrm{~L} / \mathrm{m}^{2} . \mathrm{h}$, backwash duration $=2$ minutes, aeration flow rate $=200 \mathrm{~L} / \mathrm{m}^{2}$ membrane area $/ \mathrm{h}$ ).

Over the 50 hour duration of each experiment, it can be seen that allowing the transmembrane pressure increase each cycle to increase from 1.5 to $3 \mathrm{kPa}$ had minimal effects on the level of membrane fouling. This is indicated by the 2 curves being almost the same after 15 hour of operation.

However, as the allowable transmembrane pressure increase each cycle was extended to $4.5 \mathrm{kPa}$, the fouling became more significant and there was a noticeable divergence of the transmembrane pressure versus time curve. 
Initially, backwashing after a $1.5 \mathrm{kPa}$ TMP increase each cycle allowed the SSMFS to operate at a slightly higher permeate flux. However, after approximately 15 hours of operation, allowing the transmembrane pressure increase each cycle to increase from 1.5 to $3 \mathrm{kPa}$ was found to have minimal effects on the permeate flux. This is indicated by the 2 curves being almost the same after 15 hours of operation until the end of the experiments.

However, as the allowable transmembrane pressure increase each cycle was extended to $4.5 \mathrm{kPa}$, a relatively higher reduction in the permeate flux was observed.

Figure 3 shows the results of the variation of the cumulative backwash permeate used through the duration of each experiment for varied amounts of allowable transmembrane pressure increases each cycle.

Figure 3 clearly shows that as the allowable TMP rise per filtration cycle is increased, the cumulative backwash permeate decreases. This is because the increase in TMP per filtration cycle extends the duration between successive backwashes, leading to a reduced number of backwashes and subsequently the amount of backwash permeates used over a given period of time.

From this series of short-term experiments, a suitable allowable TMP increase per filtration cycle was chosen as $3 \mathrm{kPa}$. Reducing this value had no significant effect on reducing the rate of membrane fouling (Fig. 2), however it reduced the productivity through the increased backwash permeate and time for backwashing (Fig. 3). Increasing this TMP value had adverse effects on membrane fouling and also the productivity of the system.

In conclusion, the $3 \mathrm{kPa}$ allowable transmembrane pressure increase each cycle was chosen for use in the longer term experiments because:

- $3 \mathrm{kPa}$ was not too high resulting in significant membrane fouling that would require the filtration system to be prematurely stopped and also there was not a rapid permeate flux decline that would cause the system productivity to be reduced through operating at extended periods of decreased permeate flux; and

- $3 \mathrm{kPa}$ was not too low resulting in excessively frequent backwashing that would adversely affect the productivity of the system without and justifiable improvements to the permeate flux of the system.

\subsection{Long-term experiments}

Figure 4 shows the results of the increase of the transmembrane pressure over a 14 day period of each experiment with no PAC replacement and also with $1.5 \%$ PAC removal and replacement per day.

The results indicate that the replacement of $1.5 \%$ of the PAC per day resulted in a reduced TMP increase over the duration of the experiments. The $1.5 \%$ replacement

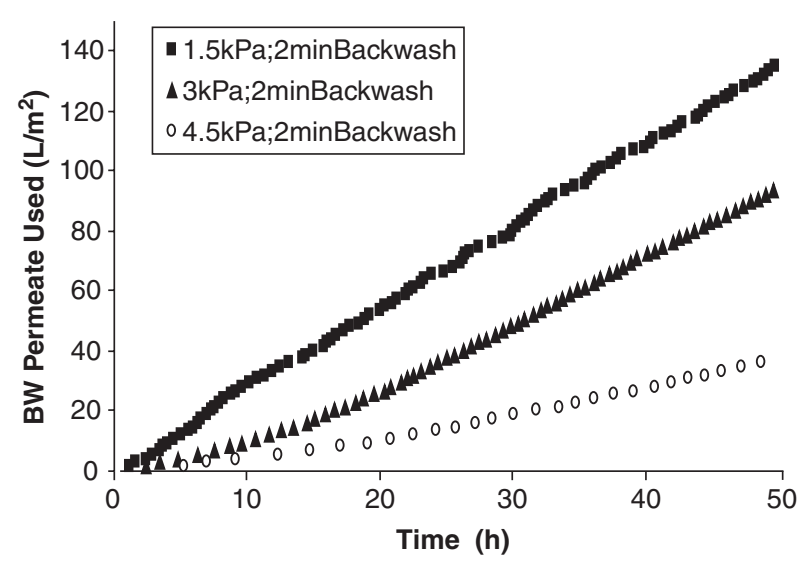

Fig. 3. Cummulative backwash permeate used versus time for different allowable transmembrane pressure increases each cycle (membrane area $=6 \mathrm{~m}^{2}$, initial permeate flux $=$ $20 \mathrm{~L} / \mathrm{m}^{2} . \mathrm{h}$, backwash flux $=40 \mathrm{~L} / \mathrm{m}^{2} . h$, backwash duration $=$ 2 minutes, aeration flow rate $=200 \mathrm{~L} / \mathrm{m}^{2}$ membrane area $/ \mathrm{h}$ ).

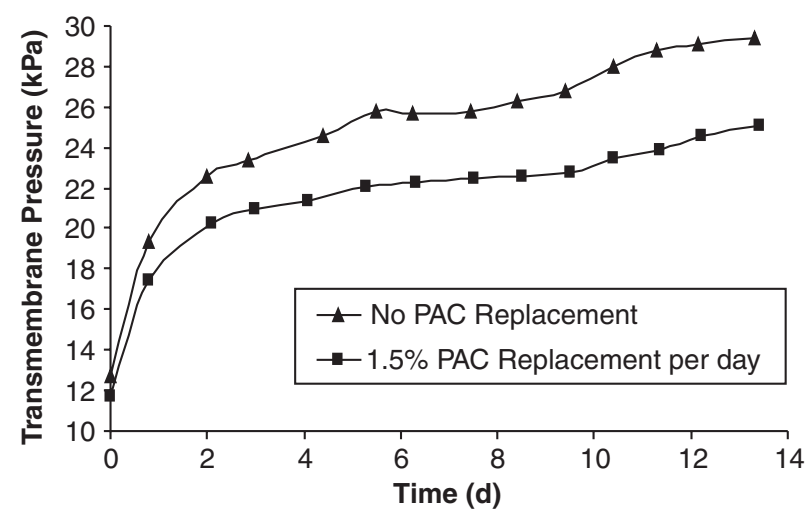

Fig. 4. Transmembrane pressure versus time for experiments with a) $1.5 \%$ per day PAC replacement and b) without PAC replacement (membrane area $=6 \mathrm{~m}^{2}$, initial permeate flux $=20 \mathrm{~L} / \mathrm{m}^{2} . \mathrm{h}$, backwash flux $=40 \mathrm{~L} / \mathrm{m}^{2} . \mathrm{h}$, backwash initiation set-point $=3 \mathrm{kPa}$ TMP rise, backwash duration $=$ 2 minutes, $\mathrm{PAC}$ dosage $=2 \mathrm{~g} / \mathrm{L}$, aeration flow rate $=200 \mathrm{~L} / \mathrm{m}^{2}$ membrane area/h).

involved the removal of 7.5 L of the PAC slurry mixture from the $500 \mathrm{~L}$ tank-membrane system and the replacement of $15 \mathrm{~g}$ of PAC. The total amount of PAC present in the tank-membrane system is $1000 \mathrm{~g}$. (ie: $2 \mathrm{~g} / \mathrm{L}$ of the tank volume). Therefore, the removal of $1.5 \%$ of the system volume (ie: tank volume of $500 \mathrm{~L}$ ) from the membrane column and PAC replacement has significant benefits in terms of reducing the increase of transmembrane pressure over time. This advantage was derived from adopting a side stream membrane configuration. The relative costs of the energy from operating the system at a higher transmembrane pressure and the costs of the additional chemicals and downtime for intensive chemical cleaning of the membrane versus the costs of the replacement of PAC and its disposal can be used to economically validate 
the effectiveness of operating the system with or without PAC removal and replacement.

Figure 5 shows the results of the variations in the permeate flux over a 14 day period of each experiment with no PAC replacement and also with $1.5 \%$ of PAC removal and replacement per day.

The results of Fig. 5 indicate that the PAC replacement allowed an increased permeate flux to be maintained throughout the duration of the experiment. Some of the success of this can also be attributed to the daily removal of the particulate matter, slime and algae that had accumulated in the membrane column.

Therefore, the higher permeate flux resulting through periodic PAC removal and replacement, allowed an increased volume of wastewater to be treated for a given membrane area. The relative costs of the purchase of additional membrane area versus the costs of the additional replacement PAC and its disposal can be used to economically validate the effectiveness of operating the system with or without PAC removal and replacement.

Figure 6 shows the results of the variation of the cumulative backwash permeate used over a 14 day period of each experiment a) with no PAC replacement and also b) with $1.5 \%$ PAC removal and replacement per day.

The results of Fig. 6 indicate that the PAC replacement reduced the required amount of backwash permeate throughout the experiment (by $14.7 \%$ over the 14 days of operation). Through the removal of the PAC slurry mixture and the replacement of the PAC, the interval of time required to reach the $3 \mathrm{kPa}$ transmembrane pressure increase each cycle (that initiated the backwash) was extended, increasing the productivity of the system.

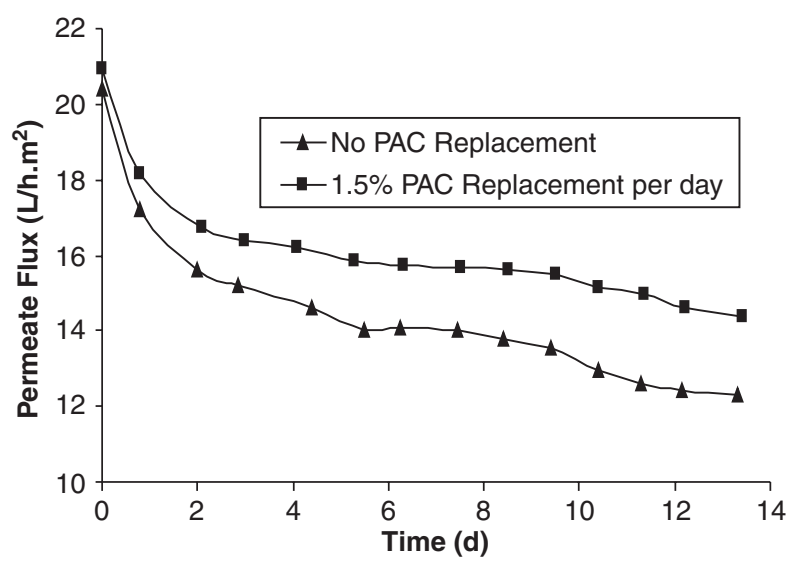

Fig. 5. Permeate flux versus time for the experiments. a) with $1.5 \%$ per day PAC removal and replacement and $b$ ) without PAC replacement (membrane area $=6 \mathrm{~m}^{2}$, initial permeate flux $=20 \mathrm{~L} / \mathrm{m}^{2} . \mathrm{h}$, backwash flux $=40 \mathrm{~L} / \mathrm{m}^{2} . \mathrm{h}$, backwash initiation set-point $=3 \mathrm{kPa}$ TMP rise, backwash duration = 2 minutes, PAC dosage $=2 \mathrm{~g} / \mathrm{L}$, aeration flow rate $=200 \mathrm{~L} / \mathrm{m}^{2}$ membrane area/h).

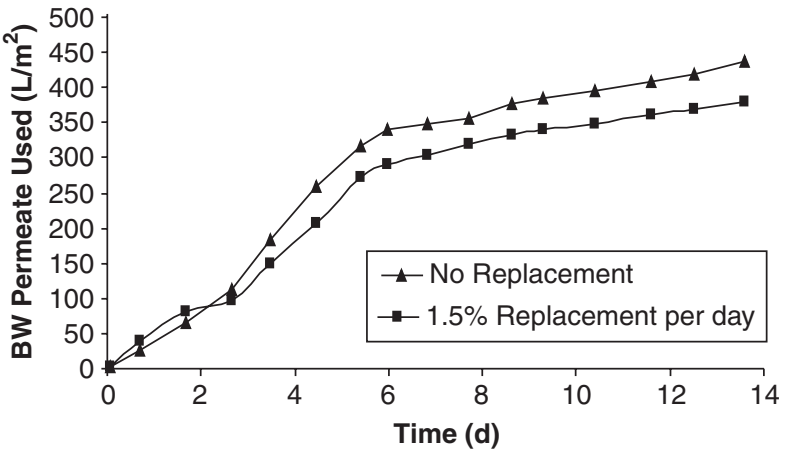

Fig. 6. Cumulative backwash permeate used versus time for the experiments a) with $1.5 \%$ per day PAC removal and replacement and b) without PAC replacement (membrane area $=6 \mathrm{~m}^{2}$, initial permeate flux $=20 \mathrm{~L} / \mathrm{m}^{2} . h$, backwash flux $=40 \mathrm{~L} / \mathrm{m}^{2} . h$, backwash initiation set-point $=3 \mathrm{kPa}$ TMP rise, backwash duration $=2$ minutes, PAC dosage $=2 \mathrm{~g} / \mathrm{L}$, aeration flow rate $=200 \mathrm{~L} / \mathrm{m}^{2}$ membrane area $/ \mathrm{h}$ ).

Some of the success of this can also be attributed to the daily removal of the particulate matter, slime and algae that had accumulated in the membrane column.

The average turbidity removal efficiency of the system was found to be over $98 \%$. This is very beneficial to reuse projects as turbidity leads to a lot of fouling and blocking problems, especially in irrigation projects. The effluent turbidity $(\sim 0.16 \mathrm{NTU})$ was actually found to be significantly less than that of the local drinking water ( 1.1 NTU).

\section{Conclusion}

- Through an investigation of the amount of fouling each cycle that can be restored through backwashing over a short-term, a good operating point for long-term operation can be developed. In the case of the SSMFS being used in the treatment of secondary treated sewage effluent, allowing the TMP to increase to $3 \mathrm{kPa}$ each cycle before backwashing was found to be optimal. This allowed the backwashing to occur often enough to prevent significant fouling and the cake layer from becoming irreversible in nature. It also avoided backwashing too frequently and causing a decrease in the productivity of the system.

- Periodic removal of $1.5 \%$ of the PAC slurry mixture (7.5 L out of 500L) and PAC replacement $(15 \mathrm{~g} / \mathrm{d})$ was found to have a positive impact on membrane fouling, permeate flux, backwash permeate required and membrane permeability. The removal of the PAC slurry mixture from the membrane column also helped by reducing the accumulated solids, algae and slime from the membrane fibre bundle. 


\section{Acknowledgements}

This work on development of a new, efficient and cost-effective advanced membrane bioreactor for municipal wastewater treatment (CG080065) was carried out through the funding of DEST-ISL program at castle Hill STP. The authors like to acknowledge the help rendered by the plant manger and all technical staff in Castle Hill STP during the experimental study. The authors also would like to acknowledge the support of Greg Allen of Sydney Water who is member of the DEST project.

\section{References}

[1] W.S. Guo, W.G. Shim, S. Vigneswaran and H.H. Ngo, J. Memb. Sci., 247(1) (2005) 65-74.

[2] H.K. Shon, S. Vigneswaran, In. S. Kim, J. Cho and H.H. Ngo, Wat. Res., 38(7) (2004) 1933-1939.

[3] T. Lebeau, C. Lelievre, H. Buisson, D. Cleret, L.W. Van de Venter and P. Cote, Des., 117(2) (1998) 219-231.

[4] P.J. Smith, S. Vigneswaran, H.H. Ngo, H. Nguyen and R.B. Aim., J. Memb. Sci., 255(1-2) (2005) 99-106.

[5] P.J. Smith, S. Vigneswaran, H.H. Ngo, H. Nguyen and R.B. Aim., J. Memb. Sci., 278(1-2) (2006) 381-389. 